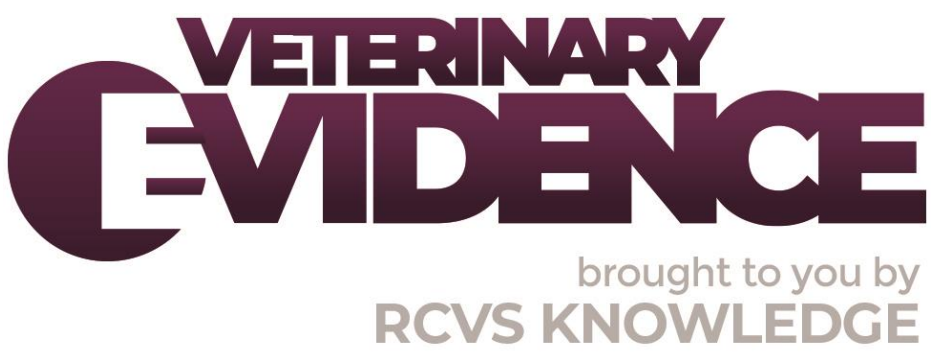

\title{
Thank you to our 2020 reviewers
}

Dr Kit Sturgess MA VetMB PhD CertVR DSAM CertVC FRCVS ${ }^{1 *}$

\footnotetext{
${ }^{1}$ Vet Freedom Ltd Brockenhurst, Hampshire, SO42 7QT

*Corresponding Author (kit.sturgess@btopenworld.com)
}

ISSN: 2396-9776

Published: 11 Jan 2021

in: The Veterinary Evidence journal Vol 6, Issue 1 DOI: 10.18849/VE.V6I1.464 
2020 will be a year to remember! One of the standout features for me has been the speed with which 'science' has responded to the crisis in terms of developing and disseminating new information to the community highlighting the importance of digital communication - a space that Veterinary Evidence comfortably occupies. The availability of pre peer-reviewed papers has become the norm but it has also emphasised the essential need and benefit of the peer-review process as a significant number of pre-review papers have not made it through to 'publication' as issues were identified during the peer-review process.

As Editor-in-chief it makes me proud and thankful that Veterinary Evidence has a strong but agile peer-review process and I would like to thank all of our editors and reviewers for their continued support and their diligence in meeting demanding timelines during these challenging times allowing Veterinary Evidence to publish more content than ever before. Without your highly valued knowledge, expertise and insights Veterinary Evidence would not be growing into the key knowledge source that it is today.

The Veterinary Evidence Editorial Board Meeting was held for the first time digitally on 7 December with the largest number of editorial board members able to attend. Members from across the globe were able to take part in wide and varied discussions around the development of the journal, resulting in important strategic initiatives and some key action points to pursue. The availability of the board to attend digitally will facilitate more frequent meetings allowing the journal to be more inclusive, and responsive to the changing landscape, as well as providing a digital recording of the event available for those board members unable to attend.

Key areas discussed included development of the format of PICOs and further refining the process for approving them, strategies to encourage engagement and submissions from veterinary nurses, and the development of policies to encourage diversity and inclusion within the board and contributors to the journal, as well as ways to increase the reach of the journal. Having only been Editor-in-chief since September, I have been very impressed by how active and dedicated our reviewers and board members are and how dynamic and forward-looking Veterinary Evidence is as it matures into a key contributor to veterinary literature. None of this would be possible without your support for which I am very grateful.

\author{
Adewole Adekola \\ Jane Alexander \\ Fergus Allerton \\ Isabel Amores-Fuster \\ Davina Anderson \\ Debbie Archer \\ Sarah Baillie \\ Elizabeth Baines \\ Kayleigh Barker \\ Simon Bate \\ Kieran Borgeat \\ Jackie Brearley \\ Jenny Brown \\ Louise Buckley \\ Valentina Busin \\ Charles Caraguel \\ James Carmalt \\ Tim Charlesworth \\ Jacqueline Cole \\ Eithne Comerford
}


Francesca Compostella

Rachel Conwell

Matthieu Cousty

Janet Daly

Sean David Langton

Janny de Grauw

Luisa De Risio

Michael De Cozar

Laura Dixon

Dr Elizabeth Mclnnes

Jacklyn Ellis

Debbie Emmerson

Virginia Fajt

Erik Fausak

Dr Fiona Margaret Lovatt

Myra Forster-van Hijfte

Sam Franklin

David G Thomas

Jennifer Garcia

Barbara Glanemann

Merran Govendir

Dai Grove-White

Matt Gurney

Kelly Hall

Martin Hawes

Alastair Hayton

Guy Hinnigan

John Hird

Soon Hon Cheong

Jodie Hughes

Karen Humm

Jo Ireland

William John Mcluskie McFadzean

Stephen Jones

Nicolette Joosting

Alastair Kay

Latifa Khenissi

Christopher Leighton Norkus

Zofia Lisowski

Kate Loomes

Gwendoline Louise Covey-Crump

Panayiotis Loukopoulos

Cassie Lux

Sohier M Syame

Tim Mair

Clare Margaret Knottenbelt

Michelle McArthur

Anna Meredith

Tristan Merlin

Duncan Michael Barnes

Andy Morris 
John Munday

Malcolm Ness

Constance Neville White

Margaret Nolan

Conor O'Halloran

Kazuya Oikawa

Joanne Oultram

James Oxley

Catherine Oxtoby

Nick Parkinson

James Patrick Crilly

Sebastian Patrick Arlt

Catrina Pennington

Roberta Perego

Robert Pettitt

Kirstie Pickles

Simon Platt

Nina R Kieves

Nicki Reed

David Rendle

Jacqueline Renee Cole

Paul Roger

Roger Smith

Suzanne Rogers

Silke Salavati

Rebecca Schofield

Michael Schoonover

Gonçalo Serrano

Tom Shaw

Virginia Sherwin

Ellen Singer

Eva Spada

Bryden Stanley

Mike Steele

Frank Steffen

Siddharth Sudunagunta

Adam Swallow

Elisabeth Swann

James Swann

Faye Swinbourne

Collette Taylor

Sam Taylor

Mary Thompson

Chris Thomson

Tom Towers

Andrew Van Eps

Elke Van der Vekens

Nieky van Veggel

Helene Vandenberghe

Claire Weeks

Richard White 
Adele Williams

Mikolaj Wojciechowski

Maurice Zandvliet 


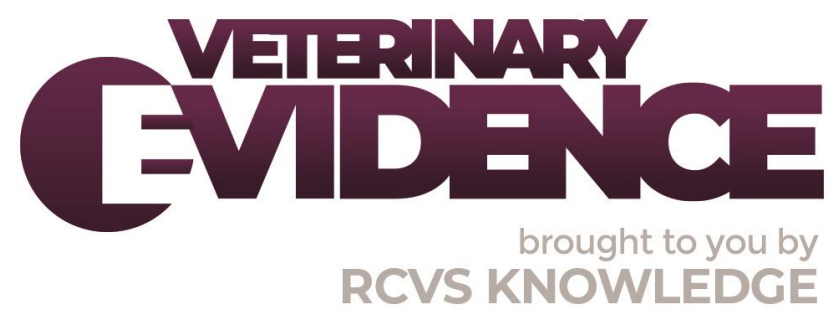

\section{Intellectual Property Rights}

Authors of Knowledge Summaries submitted to RCVS Knowledge for publication will retain copyright in their work, and will be required to grant RCVS Knowledge a non-exclusive license of the rights of copyright in the materials including but not limited to the right to publish, re-

publish, transmit, sell, distribute and otherwise use the materials in all languages and all media throughout the world, and to license or permit others to do so.

\section{Disclaimer}

Any opinions expressed in articles and other publication types published in Veterinary Evidence are the author's own and do not necessarily reflect the view of the RCVS Knowledge. Veterinary Evidence is a resource to help inform, and the content herein should not override the responsibility of the practitioner. Practitioners should also consider factors such as individual clinical expertise and judgement along with patient's circumstances and owners' values. Authors are responsible for the accuracy of the content. While the Editor and Publisher believe that all content herein are in accord with current recommendations and practice at the time of publication, they accept no legal responsibility for any errors or omissions, and make no warranty, express or implied, with respect to material contained within.

For further information please refer to our Terms of Use.

RCVS Knowledge is the independent charity associated with the Royal College of Veterinary Surgeons (RCVS). Our ambition is to become a global intermediary for evidence based veterinary knowledge by providing access to information that is of immediate value to practicing veterinary professionals and directly contributes to evidence based clinical decision-making.

https://www.veterinaryevidence.org/

RCVS Knowledge is a registered Charity No. 230886.

Registered as a Company limited by guarantee in England and Wales No. 598443.

Registered Office: Belgravia House, 62-64 Horseferry Road, London SW1P 2AF

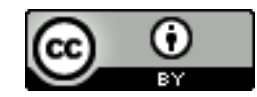

This work is licensed under a Creative Commons Attribution 4.0 International License. 